\title{
A knowledge system to support manufacturing knowledge during preliminary design
}

\author{
S. L. MOUNTNEY†, J. X. GAO*\$ and S. WISEALL§ \\ $\dagger$ Department of Manufacturing, Cranfield University, Cranfield, \\ Bedfordshire, MK43 0AL, UK \\ $\$$ School of Engineering, University of Greenwich at Medway, Chatham Maritime, \\ Kent, ME4 4TB, UK \\ $\S$ Department of Manufacturing Technology, Rolls-Royce plc, \\ PO Box 31, Moor Lane, Derby, DE24 9BD, UK
}

\begin{abstract}
The integration of manufacturing knowledge into the product introduction process is presented as a knowledge management problem. Concurrent engineering techniques are highly effective in sharing manufacturing knowledge, particularly for the re-use of knowledge at the detail design stage when the geometry has been developed. This research considers the use of manufacturing knowledge in the earlier, preliminary stage of design where the geometry is not so developed and where development of manufacturing technology may be required. An exploratory case study was carried out with a manufacturer of gas turbine engines for the civil aviation market. Semi-structured interviews were carried out to investigate the manufacturing knowledge required and its format. Using a data-driven analysis, a thematic code was developed and three themes emerged: manufacturing impact, expressions of impact and knowledge type. These themes indicate the requirement for a hybrid social-technical system to support both the tacit and explicit elements of manufacturing knowledge. An indication of the maturity of the manufacturing process also emerged as a major requirement in order to synchronize manufacturing technology developments with future product requirements. A prototype knowledge system is now being developed to meet the requirements identified through the coding analysis. The specification of the system, which uses a combination of information and social systems, is discussed.
\end{abstract}

Keywords: Manufacturing knowledge; New product introduction; Knowledge management

\section{Introduction}

Information to support manufacturing process decisions needs to be available as early as possible during the design process to prevent increasing costs and risk as projects progress. The product introduction process has become the focus of

\footnotetext{
*Corresponding author. Email: j.gao@gre.ac.uk
} 
attention, with the need for knowledge management techniques to facilitate the sharing of information and knowledge relating to all stages of the product life cycle.

In complex products, step changes in the design requirements to meet rising performance targets can result in the need for radical changes to component material properties, configuration and geometry. Consequently, new manufacturing technology processes need to be developed to achieve these geometries. Thus, a necessity in new product introduction in this sector is the ability to integrate knowledge of manufacturing technology innovations into the design process in a timely and appropriate way. To mitigate risk it is necessary to make this knowledge available as early in the design process as possible.

This paper specifies the requirements for a knowledge system which advises designers of the manufacturability of a product for the purpose of new product introduction, focusing on the sharing of manufacturing knowledge acquired during manufacturing technology innovation. Key to this is a measure of the maturity of the process capability during new manufacturing technology development. The requirements for such a system have been derived from a review of existing research in the area and the results of an exploratory case study which investigated the nature of manufacturing knowledge required by designers during the preliminary stage of the design process. The subject of the case study is a major manufacturer of gas turbine engines for the civil aerospace market.

\section{Research background}

\subsection{Concurrent engineering}

The systematic approach to the design process is indicative of the methodological approach adopted widely in Europe and the US (Pahl and Beitz 1988). The sequential nature of this process can be a problem in that the design may reach a stage of maturity before its manufacturability has been assessed. This can lengthen development times and lead to inefficient or unnecessarily costly manufacturing processes. Concurrent engineering (CE) and associated techniques such as design for manufacture (DFM) aim to reduce the cost of the component and its developmental lead time by considering a proposed design solution in terms of ease of manufacture as early as is practicable (Edwards 2002, O'Driscoll 2002). Such techniques have resulted in often substantial lead time reductions and cost reductions. However, the DFM technique does not account for other design requirements which may be required simultaneously during the embodiment stage. A further observation of DFM is that there is an assumption that all the manufacturing processes selected are capable and proven. This does not account for the introduction of new manufacturing technologies and their effects on the product, a problem which this research aims to address.

Successful implementations of CE techniques have usually been team-based, using methods such as IPTs (integrated product teams). Researchers have recognized the opportunity to develop ICTs (integrated computer technologies) to support this team-based approach by providing fidelity and quality of data. The challenge in developing such systems is ensuring that the information is structured in such a way to make it communicable between systems (Young et al. 2004). 


\subsection{Knowledge management}

The sharing of design and manufacturing knowledge across the product introduction process can be viewed as a knowledge management problem. Features are a popular method of exchanging design and manufacturing knowledge in CAD/CAM platforms to assist the decisions of designers (Mandorli et al. 2003). A feature is defined as a collection of geometry to which some engineering significance can be assigned. Such representation enables knowledge pertaining to that feature to be structured and represented for different life cycle domains, such as design or manufacturing. However, the domain-specific nature of features limits their ability to be used in knowledge sharing across different domains. Techniques such as multifeature view mapping, where features from one domain are translated into a second domain have been developed to overcome this problem but results in a number of different product models being stored (Bronsvoort and Noort 2004). A further limitation is that the geometric nature of a feature requires the product design to have reached a stage of maturity (typically detail design) for the technique to be successfully deployed, thus limiting their use to later life cycle domains. In other cases where features have been used during the concept (pre-geometry) stage, the definition of a feature has shifted to that of a carrier of information relative to a life cycle phase, rather than the traditional form feature view (Brunetti and Golob 2002, Bronsvoort and Noort 2004). Therefore, in developing information systems to share manufacturing and design knowledge for re-use, the preferred approach is to create knowledge models to structure and represent knowledge and information to be shared, in the form of a product model and in cases of manufacturing knowledge, an additional process model. Often represented as class-based UML diagrams, these models enable different domains to be modelled and translated (Canciglieri and Young 2003). Features have certainly proven to be useful as part of the product structure, usually in representing manufacturing features. In one example of such a system, a product model and a manufacturing model were developed to support concurrent engineering (Young et al. 2001). The models were linked by their resources and processes and the manufacturing strategy at feature level. This created a flexible method of linking manufacturing features to a method of manufacture. In a further example, a multi-level knowledge model was used for design and manufacturing knowledge management based on the product structure (Bordegoni and Cugini 2002). Manufacturing constraints were represented as rules and parameters mainly related to the selected configuration and material of the component. Other examples have sought to include some assessment of manufacturability in the system, such as a feature-based information system created to assess manufacturability during the early design stages, on an operation-by-operation basis (Sharma and Gao 2002). The manufacturing options are compared by cost with no assessment of manufacturing capability. In a further example, a knowledge management database was developed to support manufacturing knowledge in design using a feature-based product model and an integrated process model (Balogun et al. 2004). Specific operations from the process model linked into the product model at component and feature levels. The database functionality includes assessment of manufacturing processes, costs and capability. Being feature-based, the latter two systems rely on a certain maturity of geometric definition before a manufacturing analysis can be carried out. 


\subsection{Limitations of ICTs: the tacit dimension}

Despite the development of ICTs to support this area, it has been recognized that the implementation of knowledge management systems has not produced the return on investment anticipated (Johannessen et al. 2001, Walsham 2001). The reason cited for this lies in the definitions of explicit and tacit knowledge. Explicit knowledge is codified and structured whereas tacit knowledge is unstructured, cannot be codified and results from personal experience. A third knowledge type, implicit knowledge, signifies knowledge shared tacitly which could be codified in an explicit form (Nonaka 1994, Polanyi 1966).

It has been suggested that the poor return on investment for ICTs has occurred because although tacit knowledge is essential to the generation of explicit knowledge and knowledge transfer, it cannot be communicated in an ICT system. Difficulties arise when there is a concentration on explicit knowledge transfer (i.e. system development) at the expense of tacit knowledge. There is no substitute for a human interface; therefore a shared context needs to be created outside an ICT to enable the exchange of tacit knowledge (Fahey and Prusak 1998). The human aspect of knowledge management techniques should therefore be considered in addition to ICT implementation. Social techniques, such as communities of practice and organizational translators, can facilitate the sharing and transfer of tacit knowledge (Walsham 2001) and it is important for geographically dispersed team members to have initial face-to-face contact to establish trust, which is considered a pre-requisite for sharing tacit knowledge (Roberts 2000).

Some knowledge modelling work has shown the need to use tacit and explicit knowledge. A manufacturing model was used to classify knowledge types into explicit, implicit and tacit in order to determine which information system to represent and use (Young et al. 2004). In the development of a framework to structure knowledge for the design process, information was represented as being formal (structured and codified) or informal (unstructured and not codified), analogous to Polanyi's explicit and tacit knowledge definitions (Hicks et al. 2002). Knowledge elements were constructed from formal and informal information elements. The former could be captured electronically whereas the latter required pre-processing and was seen as unreliable; therefore at least one formal information element was required for the knowledge to be credible.

\subsection{Summary of the research background}

The socio-technical approach has been adopted in this research to deal with the need to represent both tacit and explicit knowledge (Kerr et al. 2001, Mountney and Gao 2005). A whole system view is taken in creating a knowledge management solution which involves job roles and organizational structure. IT tools are specified to fit into the existing system and support the existing system. Hence, development is not purely technology-led. In the context of knowledge management for product introduction, IPTs can be seen as successful in sharing tacit knowledge, and the supporting ICTs in sharing explicit knowledge. Combining both methods systematically can be seen as an example of a sociotechnical system. 
There is currently a research gap in the development of a practical tool to demonstrate this approach. One example is the development of a tool for designers in the aerospace industry for knowledge capture, sharing and re-use (Kerr et al. 2001). Using interview and workshop data, a series of social and technical requirements were derived, aimed at improving confidence in data and knowledge capture, better indexing, search and retrieval facilities and better methods of finding and accessing individual expertise.

\section{Industrial case study}

\subsection{Methodologies used}

The focus of the case study was to investigate the nature and extent of the manufacturing knowledge used in the earlier, preliminary stages of design.

The preliminary design stage is analogous with the embodiment stage as described by Pahl and Beitz (1988). The design requirements are transformed into an initial physical design solution, represented by a graphical arrangement. The approach is adaptive (again using the Pahl and Beitz terminology) in that an existing component will be considered as a starting point for the design and the modification of this to meet the design requirements explored. This stage of design involves creativity and the systems developed to support this must therefore be flexible. Lead times for development are also decreasing, again requiring flexibility. However, such a process needs to be supported by knowledge of the highest integrity in order to reduce risk during the project life cycle.

For the purpose of the investigations, manufacturing knowledge was defined as 'knowledge which relates to the manufacturing of a product which impacts directly on the design requirements or the outcome of the design'.

Semi-structured interviews were selected as the most appropriate method to obtain the data in terms of their flexibility and timeliness. The use of story-telling to effectively communicate particular incidents and lessons learned is well known in qualitative research techniques, therefore this approach was adopted. The interviews were designed using the critical incident technique (Flanagan 1954). The critical incident in question was a specific situation encountered by the interviewee where manufacturing considerations had impacted on the design requirements or design outcome. This could be either a positive or a negative effect. In addition to the details of the impact, the interviewee was also asked how they became aware of the situation, to determine the source and format of knowledge.

The interviews were recorded and transcribed and analysed using a thematic coding technique (Boyatzis 1998). Two sets of interviews were run. The first set of interviews was with preliminary design engineers from the central team for initial data collection. The second set took place with engineers from departments which interface functionally with the central preliminary design department during the product introduction process; sub-system design and manufacturing engineers and specialists from the manufacturing technology team. The aim of the second interviews was to validate and further develop the initial code. A total of 12 interviews took place. 


\subsection{Case study results}

The code identified three main themes which indicate the use of manufacturing knowledge in the design process:

1. A knowledge of how the manufacturing process affects the design of a component (coded as 'manufacturing impacts');

2. A knowledge of how these process effects are expressed (coded as 'expressions of manufacturing impacts');

3. How these expressions of manufacturing impacts are communicated (coded as 'knowledge types').

Each theme is subdivided into three sub-themes which are described below.

3.2.1 Manufacturing impacts. The manufacturing process ultimately constrains the size and configuration of the component being designed. This is achieved directly by the process and indirectly by the effect of the manufacturing process on the material properties. The extent of this constraint can be described in increasing levels of detail, which are represented by these three sub-themes:

- Configuration: This impact is seen exclusively during the preliminary design stage when the manufacturing process constrains the general size and configuration of the component. The size and configuration boundaries of the component can be graphically represented by a 'configuration envelope'. For example, minimum allowed wall thickness of a component due to the casting process. A previous assembly becomes a single component.

- Tooling: This impact is evident during the detail design stage, where individual process operations are under consideration. The manufacturing process constrains the size and configuration of the component due to tooling clearance limitations at component level. For example, the geometry of the component is changed to allow clearance for machine tool paths during machining.

- Manufacturing geometry: This manufacturing impact was also identified during the later stages of detail sub-system design where individual process operations are under consideration. Additional geometry needs to be added to the component geometry to facilitate the manufacturing process for a specific operation. For example, the geometry of the component prior to manufacturing includes additional blocks of material either side of the component for work holding.

3.2.2 Expressions of manufacturing impact. This second theme considers how the manufacturing impacts can be expressed to communicate design considerations during the product introduction process. This theme is particularly relevant to the maturity of the manufacturing process (discussed in section 4).

- Empirical: The manufacturing process constrains the size and configuration of the component to a degree which may not be fully quantified. Its feasibility must therefore be assessed using combinations of expert judgement, experimentation, empirical numerical calculations and written/verbal comments. 
This method of expression is often seen when some process development is required. For example, a new joining method for two different and resulting discussions/communications related to this.

- Quantified: The manufacturing process constrains the size of the component to certain parameters. These parameters are expressed numerically, usually in the form of parameters or rules. For examples, minimum allowed wall thickness of a component due to the casting process, maximum forging size allowed for bought-in component of finished material.

- Standardized: The manufacturing process constrains the size and configuration of the component to a predetermined list of discrete values. These standard sizes are fixed by either an in-house or bought-out manufacturing process. For example, use of a previous part as a standard solution with no dimensional alterations made.

3.2.3 Knowledge types. The final set of sub-themes demonstrates how manufacturing knowledge can be communicated throughout the product introduction process.

- Structured: The knowledge is quantitative. It can be expressed numerically by algorithms or rules. This knowledge is generated and used during the design process. It is also repeatable across projects. It is documented in the form of parameters, dimensions, spreadsheet calculations or algorithms in expert systems and can also be expressed graphically. Knowledge is said to be 'abstracted'-it is possible (although not always preferable) to apply it without fully appreciating the circumstances in which it was created. For example, manufacturing minimums and maximums, a graphicallyrepresented parameterized feature, a spreadsheet of calculations.

- Semi-structured: The knowledge is quantitative and/or qualitative. It can be referenced and supports the design process, but is not integral to it. The need to reference the knowledge will depend on the situation, the context and the designer's own experience. The knowledge is documented in text documents. Knowledge is said to be 'embedded' - the designer needs to be able to browse and understand the context of the knowledge in order to be able to use it. Often the knowledge referenced is from outside the department. For example, details of material properties on an intranet site, project reports and emails.

- Unstructured: This knowledge type is identical to semi-structured knowledge except for its method of communication. It is not recorded and is communicated socially; hence the expert being questioned can supply some context. The knowledge can be internal to the department or external, and can be communicated using either formal or informal social networks. For examples, discussions with people, group meetings.

\subsection{Comments on the situations identified in the interviews}

The interviews identified 18 situations. Each situation has a manufacturing impact, an expression of impact and at least one knowledge type. Table 1 shows two indicative situations and their resulting classifications (although in some cases, the knowledge type could not be recalled). 


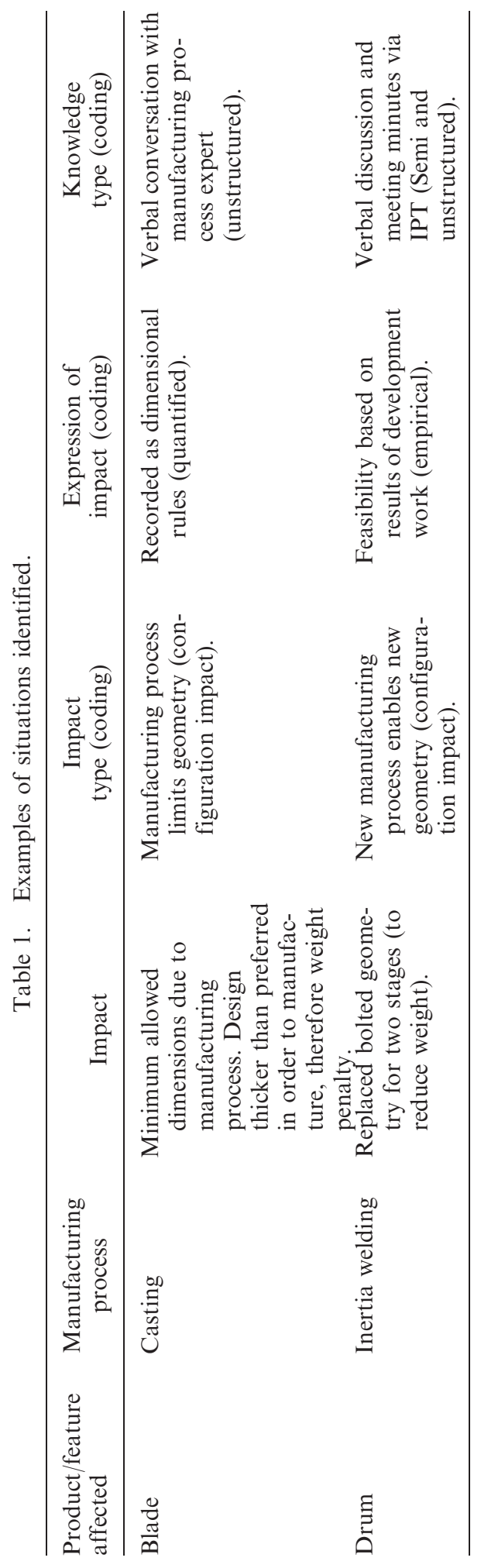


Table 2. Summary of situations.

\begin{tabular}{|c|c|c|c|c|c|}
\hline Situation & Identified by & $\begin{array}{l}\text { Process } \\
\text { stage }\end{array}$ & Expression & Impact & $\begin{array}{l}\text { Knowledge } \\
\text { types }\end{array}$ \\
\hline 1 & Designer & Early prelim & Quantified & Configuration & Unstructured \\
\hline 2 & Designer & Early prelim & Quantified & Configuration & Structured \\
\hline 3 & Designer & Early prelim & Quantified & Configuration & Unstructured \\
\hline 4 & Designer & Early prelim & Empirical & Configuration & Unstructured \\
\hline 5 & Designer & Early prelim & Standard & Configuration & $\mathrm{N} / \mathrm{K}^{*}$ \\
\hline 6 & Designer & Early prelim & Empirical & Configuration & Unstructured \\
\hline 7 & Designer & Early prelim & Empirical & Configuration & Unstructured \\
\hline 8 & Designer & Early prelim & Empirical & Configuration & $\mathrm{N} / \mathrm{K}^{*}$ \\
\hline 9 & Designer & Early prelim & Empirical & Configuration & Structured \\
\hline 10 & Designer & Early prelim & Quantified & Configuration & $\mathrm{N} / \mathrm{K}^{*}$ \\
\hline 11 & Designer & Early prelim & Empirical & Configuration & $\mathrm{N} / \mathrm{K}^{*}$ \\
\hline 12 & Designer & Early prelim & Standard & Configuration & $\mathrm{N} / \mathrm{K}^{*}$ \\
\hline 13 & Designer & Early prelim & Standard & Configuration & $\mathrm{N} / \mathrm{K}^{*}$ \\
\hline 14 & Designer & Early prelim & Standard & Configuration & $\mathrm{N} / \mathrm{K}^{*}$ \\
\hline 15 & $\begin{array}{c}\text { Manufacturing } \\
\text { technologist }\end{array}$ & Later prelim & Empirical & Configuration & $\begin{array}{l}\text { Semi and } \\
\text { unstructured }\end{array}$ \\
\hline 16 & $\begin{array}{c}\text { Manufacturing } \\
\text { technologist }\end{array}$ & Later prelim & Quantified & Configuration & All \\
\hline 17 & $\begin{array}{c}\text { Manufacturing } \\
\text { technologist }\end{array}$ & Later prelim & Empirical & Tooling & All \\
\hline 18 & $\begin{array}{l}\text { Manufacturing } \\
\text { engineer }\end{array}$ & Detail & Standard & $\mathrm{M} / \mathrm{F}$ geometry & Structured \\
\hline
\end{tabular}

*In a number of cases, the method of knowledge transfer could not be recalled.

There is no obvious one-to-one correlation between particular occurrences of manufacturing impact, expression of impact or knowledge type. Each manufacturing impact has a range of associated expressions of impact and knowledge types. A summary of occurrences can be seen in table 2 .

Additionally, there is no obvious correlation between expressions of impact and knowledge types. In some cases all the knowledge types were used to firstly represent and calculate the knowledge and then communicate it to other team members. Indicative situations are shown in table 3.

\section{Analysis of the results}

In preliminary design, the component configuration constraints imposed by the manufacturing process must be considered in a trade-off with other design requirements (i.e. sizing limitations from lifting, aerodynamic requirements) with the 'worst case' sizing being the final design case. The constraints can be inferred by considering a previous component (and manufacturing process) as a starting point for the previous design, analogous to the adaptive design approach as described by Pahl and Beitz (1988). In addition, the properties of the material selected for the component (from the functional requirements) will constrain the manufacturing processes available to the designer. The selected manufacturing 


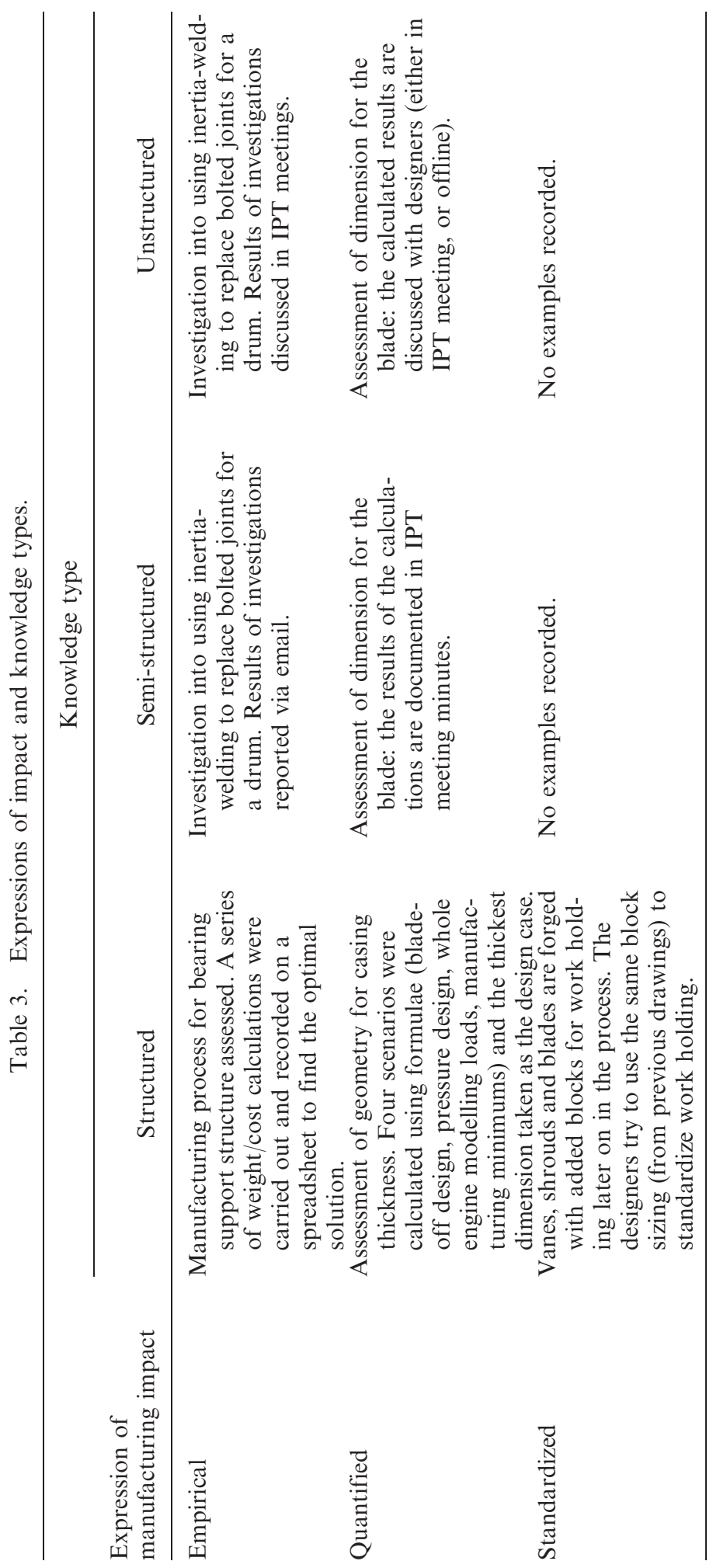




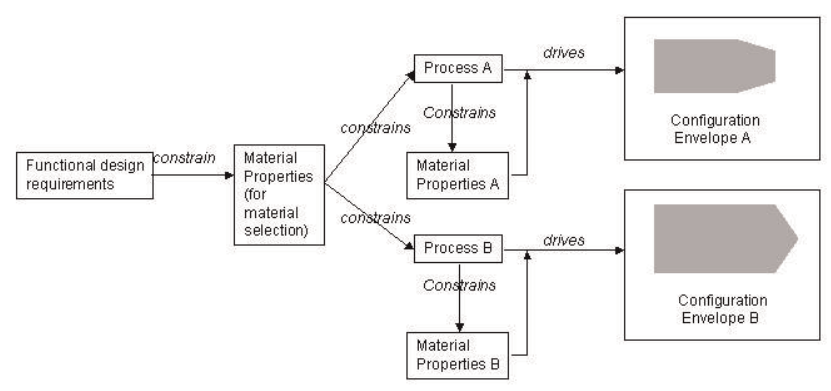

Figure 1. Impact of the manufacturing process on the component configuration.

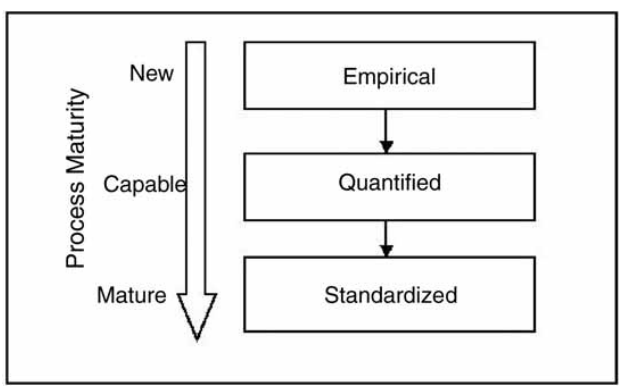

Figure 2. Maturity of manufacturing process and expressions of impact.

process will then further constrain the material properties and the component configuration. This paper proposes that, in the case of product innovation, these constraints may have a positive or negative effect on design creativity. At one extreme, a manufacturing process could constrain component dimensions to the extent that they cannot be changed. Alternatively, the development of new manufacturing technology changes the available 'configuration envelope' for the component and makes new configurations and sizings available to the designer. This is illustrated in figure 1 . The ability to share the configuration impacts influenced by tooling and additional manufacturing geometry from the detail stages of design in preliminary design would enable such impacting information to become available earlier in the design process.

This paper proposes a link between an appropriate method of impact expression and the maturity of the manufacturing process capability which can be seen in figure 2. If a method of manufacture is under development, significant trials and experimentation are required in ascertaining its feasibility for use on a new engine project. The degree of experimentation required depends on how the method of manufacture has been applied on previous projects. At this stage of development, it may not be possible to express definite quantifiable rules for new components. A range of values may be proposed, or in the case of a new process, no rules may have yet been derived. Consequently, the empirical expression of impact would be the most suitable for expressing the manufacturability issues. Once some degree of maturity of process capability has been reached, the results of the experimentation 
can be expressed as rules, using the quantifiable method of expression. For a very mature manufacturing process, it may be possible to standardize the manufacturing process and hence the component/feature geometry into a discrete range of values.

There is an assumption that all manufacturing processes are mature and capable and can be applied to all projects repeatedly (Balogun et al. 2004). By using a combination of expressions of manufacturing impact and a method of determining the manufacturing technology development state, an indication of manufacturing process maturity can be fed back to the preliminary design stage. The effect of such manufacturing technology can positively influence the future component configuration in line with new design requirements. This in turn will provide a dynamic environment in which product innovation can be achieved in tandem with manufacturing technology innovation. The question to be addressed is how to determine when the manufacturing technology development has reached an appropriate stage to be expressed in each way.

The knowledge types unstructured, semi-structured and structured are synonymous with the definitions of tacit, implicit and explicit respectively. The use of graphics (structured knowledge) to communicate knowledge about the design and design problems was of paramount importance. Furthermore, structured knowledge appears to be of particular importance during the preliminary stage as a method of representing the various trade-offs of design requirements. This level of abstraction appears to be necessary to enable these trade-offs to be managed. However, structured knowledge also has limited use. It is important that a context is supplied otherwise it may be wrongly applied.

A method of supplying that context exists with semi-structured knowledge. However, limitations also exist. The context of semi-structured knowledge needs to be known for searching and the knowledge may not actually be represented in the required context. There are also practical problems such as meeting maintenance and security requirements. Unstructured knowledge was the main method for exchange of knowledge, both formally and informally, within the department and across departments. For example, the benefits and efficacy of the use of IPTs in the later preliminary and detail design stages of the design process were widely evident, as were the use of informal networks for earlier preliminary design. There was evidence of the personal use of different knowledge types during knowledge transfer, for example, discussing a design problem with colleagues and then noting the results in a notebook (transfer from unstructured to semi-structured knowledge). These findings indicate the importance of utilizing all knowledge types, a view reinforced by current research.

\section{The knowledge system in development}

It is proposed that a knowledge system to support the use of manufacturing knowledge during the preliminary design stage should meet the following conceptual requirements:

- Due to the importance of a graphical scheme of the design during the design process, the system developed should directly interface with a graphical representation of the product. 


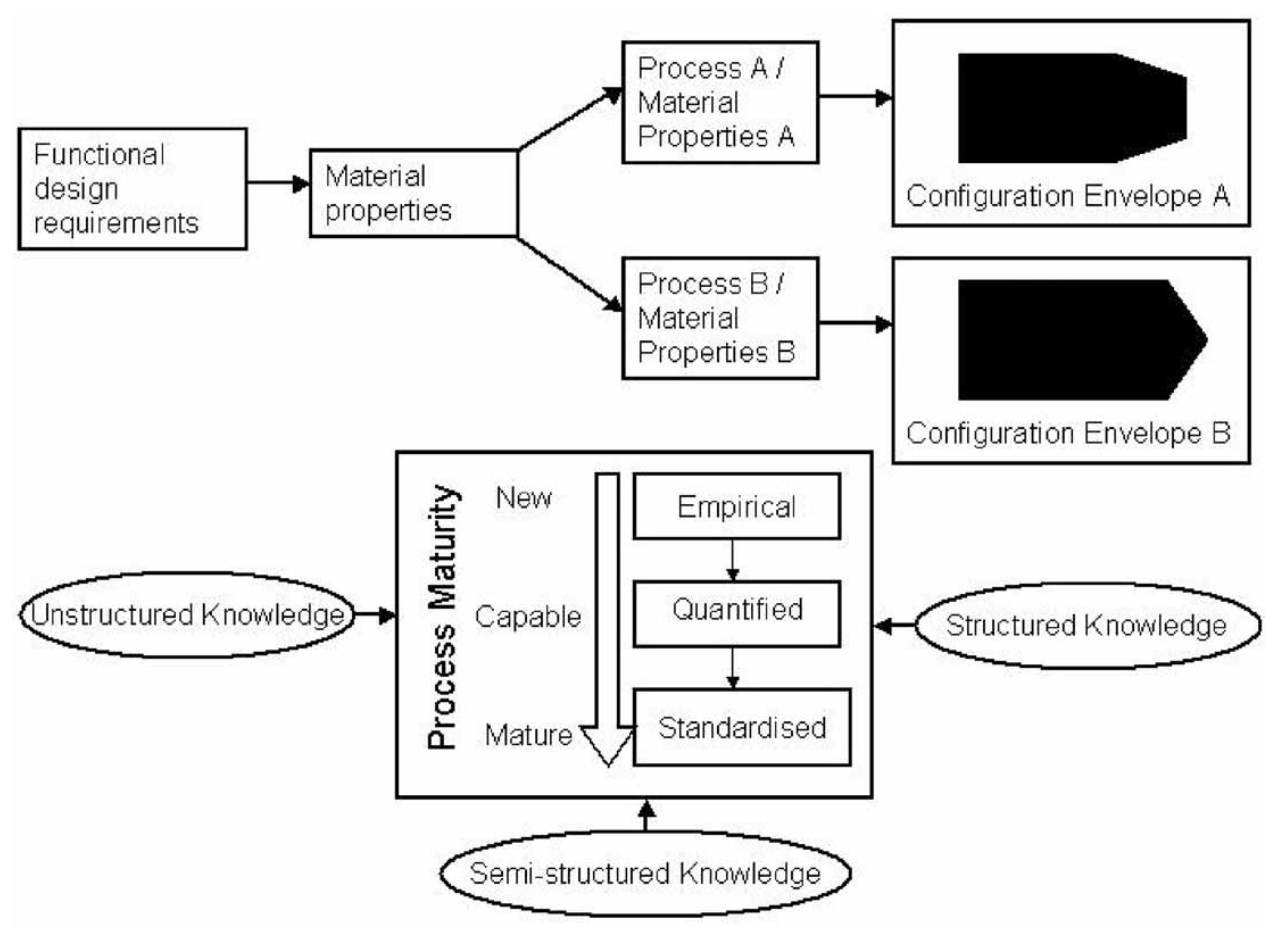

Figure 3. Conceptual requirements of knowledge system.

- The manufacturing process technology should be communicated in terms of constraints to the component configuration. It is also imperative that there is an assessment of the maturity of manufacturing technology and its capability.

- The system developed should utilize all the knowledge types and therefore be a combination of information and social systems.

A diagrammatic representation of the conceptual requirements can be seen in figure 3.

Current project work is now focused on the development of the knowledge system NOMAD to support the use of manufacturing knowledge in preliminary design. A socio-technical approach will be used to develop a system which complements and supports the existing design process activities. Due to this approach, the system is referred to as a 'knowledge system' rather than a 'knowledge management system' as the latter term has been used widely to describe ICTs. There will be two elements of this development:

1. The development of (a) social system(s) to facilitate the exchange of unstructured (tacit) knowledge.

2. The development of a prototype knowledge management tool to capture structured (explicit) and semi-structured (implicit) knowledge and to provide 
contact details to facilitate the creation of a social network (unstructured knowledge).

Investigations into the requirements for the social system are ongoing. The next section discusses the functional requirements for the ICT element of the knowledge system.

\subsection{Functional requirements for a knowledge management system}

The knowledge management system is a database of manufacturing knowledge required for preliminary design. It includes high level information such as details of the primary process, i.e. the original material shaping process which supplies the initial part for future production operations, and the manufacturing processes associated with secondary manufacturing operations. The advisory system would operate outside a CAD tool (and therefore be used with a number of CAD applications) but could be fully integrated into its functionality. The designer would start the tool via a hypertext link from the graphical model within the CAD system. The database of information would be sourced from existing databases where appropriate.

The suitable functional requirements for a knowledge management system meeting the above conceptual requirements would be as follows:

- The system would be used in conjunction with a commercial CAD package. When a model of a component was accessed, the knowledge relating to that component and its features would automatically be accessed.

- Initially, the design process would commence by selecting a pre-defined generic model for a preferred component style. This initial generic model would contain configuration boundaries which corresponded to manufacturing process constraints. Specific geometry would then be created using 3D modelling to create the individual component.

Once the component was selected, the component material and primary manufacturing process (the main process to define the initial component configuration) could be selected. The system would then display the manufacturing constraints on the component configuration due to that process. These constraints would be displayed depending on the maturity of the manufacturing process as follows:

- If the process was mature and the constraints can be quantified or standardized, the maximum and minimum permissible dimensions would be displayed.

- If the process was under development, a best assessment of the current permissible dimensions would be displayed. If this was not possible, further information on the process development would be displayed.

In addition to the manufacturing constraints, additional information on the manufacturing process, its capability, maturity and details of any development projects would be made available as a series of http pages which could be accessed via hyperlinks. 
Secondary manufacturing processes could be accessed by clicking on the relevant feature and selecting the method of manufacture. Again, the manufacturing constraints would be displayed in the same way as for the primary processes.

The information is therefore filtered and represented to the designers using the different expressions of manufacturing impacts and knowledge types, as follows:

- Where the process is mature and capable, the manufacturing impact constraints are quantifiable or standardized rules shown as structured knowledge.

- Where the process is under development and the knowledge cannot be quantified as rules, the http hyperlinks will access semi-structured knowledge. These additional links can also supply extra background semistructured knowledge to support initial structured knowledge.

- It is appreciated that unstructured knowledge is not suitable for inclusion in an information system, however the system will feature contact names in the hyperlink as a method of facilitating the use of social networks.

Knowledge would be available using the 'minimum input-maximum benefit' maxim to ensure the most relevant information would be captured in the most suitable, brief manner. Specific templates would be designed to ensure consistency of knowledge in the http files. This is aimed at solving the issue of creating and maintaining knowledge in the system. By creating contacts in the information system, some facilitation of unstructured knowledge transfer is achieved. However, it is recognized that additional social systems are required to facilitate knowledge transfer across all types.

\section{Conclusion}

The research confirmed the importance of manufacturing knowledge during the preliminary design stage. It is necessary to consider the impact of the manufacturing process because this directly impacts on the achievable configuration and shape of the component. This can have a positive effect in that a new manufacturing process changes the component configuration envelope to enable different, more demanding design requirements to be met. It is necessary to assess this impact for early identification of manufacturing technology risks and opportunities. The impact of the manufacturing process can be expressed in three ways: empirically, quantifiably and by standardization. Each expression of impact is required to express the appropriate level of maturity for the manufacturing process. A knowledge management system to support manufacturing knowledge during the preliminary design stage must therefore represent the process impact and the three ways in which this can be expressed. Such a system must also represent knowledge across the tacitexplicit knowledge spectrum.

A prototype knowledge management system is now being developed. This system will demonstrate the requirement for a representing process maturity. A sociotechnical approach will be adopted to represent both the explicit and tacit elements of the knowledge. 


\section{Acknowledgements}

The authors would like to acknowledge the assistance and support of the project sponsor Rolls-Royce and in particular, Peter Hill, Steven Halliday, Neil Armstrong and Michael Moss.

\section{References}

Balogun, O., Hawisa, H. and Tannock, J., Knowledge management for manufacturing: the product and process database. J. Manuf. Tech. Manage., 2004, 15(7), 575-584.

Bordegoni, M. and Cugini, U., Design and manufacturing knowledge management, in PCM2002: 7th International Conference on Manufacturing and Management, 2002, Vol. 1, pp. 476-481.

Boyatzis, R.E., Thematic Analysis and Code Development: Transforming Qualitative Information, 1998 (Sage: Thousand Oaks).

Bronsvoort, W.F. and Noort, A., Multiple-view feature modelling for integral product development. CAD, 2004, 36, 929-946.

Brunetti, G. and Golob, B., A feature-based approach towards an integrated product model including conceptual design information. CAD, 2002, 32, 877-887.

Canciglieri, O.J. and Young, R.I.M., Information sharing in multiviewpoint injection moulding design and manufacturing. Int. J. Prod. Res., 2003, 41(7), 1565-1586.

Edwards, K.L., Towards more strategic product design for manufacture and assembly: priorities for concurrent engineering. Mat. \& Des., 2002, 23, 651-656.

Fahey, L. and Prusak, L., The eleven deadliest sins of knowledge management. Calif. Manage. Rev., 1998, 40(3), 265-276.

Flanagan, J.C., The critical incident technique. Psycho. Bull., 1954, 51(4), 327-358.

Hicks, B.J., Culley, S.J., Allen, R.D. and Mullineux, G., A framework for the requirements of capturing, storing and reusing information and knowledge in engineering design. Int. J. Inform. Manage., 2002, 22, 263-280.

Johannessen, J.-A., Olaisen, J. and Olsen, B., Mismanagement of tacit knowledge: the importance of tacit knowledge, the danger of information technology, and what to do about it. Int. J. Inform. Manage., 2001, 21, 3-20.

Kerr, M.P., Waterson, P.E. and Clegg, C.W., A socio-technical approach to knowledge capture, sharing and reuse in aerospace design, in Proceedings of the ASME Design and Engineering and Technical Conference, 2001, Vol. 1, pp. 267-273.

Mandorli, F., Rizzi, C., Susca, L. and Cugini, U., An approach to implement feature-based applications using knowledge aided engineering technology in feature based product life-cycle modelling, in IFIP TC5/WG5.2 and WG5.3 Conference on Feature Modelling and Advanced Design-for-the-Life-Cycle Systems (FEATS 2001), 2003, pp. 41-55.

Mountney, S. and Gao, J.X., Manufacturing knowledge to support preliminary design - an exploratory case study, in Proceedings of the 3rd International Conference on Manufacturing Research, 2005 (CD-ROM).

Nonaka, I., A dynamic theory of organizational knowledge creation. Org. Sci., 1994, 5(1), $14-37$.

O’Driscoll, M., Design for manufacture. J. Mat. Proc., 2002, 125, 318-321.

Pahl, G. and Beitz, W., Engineering Design: A Systematic Approach, 1988 (Design Council: London).

Polanyi, M., The Tacit Dimension, 1966 (Doubleday: New York, NY).

Roberts, J., From know-how to show-how? Questioning the role of information and communication technologies in knowledge transfer. Technol. Anal. Strat. Manage., 2000, 12(4), 429-443.

Sharma, R. and Gao, J.X., A progressive design and manufacturing evaluation system incorporating STEP AP224. Comp. Indust., 2002, 47, 155-167. 
Walsham, G., Knowledge management: the benefits and limitations of computer systems. Euro. Manage. J., 2001, 19(6), 599-608.

Young, R.I.M., Cutting-Decelle, A.F., Guerra, D., Gunendran, G., Das, B. and Cochrane, S., Sharing manufacturing information and knowledge in design decision and support, in IDMME 2004 Conference, 2004 (CD-ROM).

Young, R.I.M., Dorador, J.M., Zhao, J. and Cheung, W.M., A manufacturing information infrastructure to link team based design to global manufacture, in DISMM 2000: Global Engineering, Manufacturing and Enterprise Networks, 2001, PP. 283-290. 